\title{
Neuro-feedback intervention efficacy for treating children with Autism Spectrum Disorder
}

Johann Krynauw and Athena Pedro

\begin{abstract}
This study explored practitioners perceptions of a neuro-feedback intervention in treating children with Autism Spectrum Disorder's (ASD). Informants were a convenience sample of ten South African neuro-feedback practitioners registered with the Health Professions Council of South Africa (HPCSA). The data on their views on neuro-feedback treatment efficacy, with children with ASD, were collected by means of semi-structured in-depth interviews. Thematic analysis of the data suggest practitioners to perceive neuro-feedback treatment to enhance the social, mood, behaviour, academic life, and family functioning of children with ASD. Additionally, the practitioners perceived neuro-feedback treatment to assist in reducing anxiety among children with ASD.
\end{abstract}

\section{Introduction}

Autism Spectrum Disorders (ASD) are neurodevelopmental disorders characterised by abnormalities in social interaction, communication skills, and behavioural flexibility within a certain range of severity (American Psychiatric Association: APA, 2013). In South Africa, the prevalence rate of ASD is estimated at over 270 ooo people, with 5000 new cases predicted per year (Springer, van Toorn, Laughton, \& Kidd, 2013) . Children with neurodevelopmental disorders who were treated with neuro-feedback resulted with decreases in unwanted stresses and higher executive functioning abilities related to planning, organising, and completing tasks (Kouijzer, de Moor, Gerrits, Congedo, \& van Schie 2009). For that reason, neuro-feedback treatments can be of great benefit to children with ASD and their families by improving their quality of communication, as well as sociobehavioural engagement (Mohamed, 2009).

This study sought to explore South African health professional's views on the efficacy of neuro-feedback as a treatment for children with ASD. The neuro-feedback system is a highly personalised brain training software that prompts the central nervous system to help make the best use of the brain's neural resources (Mohamed, 2009). Mental health care practitioners are likely to work to address behavioural and sensory stimuli exacerbations associated with ASD by reducing acute sensitivity to environmental stimuli of hearing, smelling, tasting, and moving around (Hoffman, 2012). Children with ASD are acutely sensitive to loud noises, strong smells, and other sensory stimuli. As examples, the high stimulus environments (such as shopping malls or shopping centres) 
can be sources of agitation and discomfort. As a result of the sensory overload, a child with ASD may find it difficult to navigate and participate in typical social events with ordinary noise levels. In response, the child with ASD might react with temper tantrums; aggression, destructiveness, screaming, and running away are often associated with autism and frequently lead to dysfunctional social interaction (Hoffman, 2012). These behavioural traits extend to the child's interactions in various environments such as school; presenting severe educational challenges.

Every practitioner using neuro-feedback as an intervention has a different approach in applying the intervention. A holistic approach entails a form of healing that considers the whole person body, mind, spirit, and emotions in the quest for optimal health and wellness (Hoffman, 2012). A holistic approach may be applied singly or supplemented with other techniques such as homeopathic therapy (Eller, 2015). Homeopathic therapy is a medical philosophy and practice based on the idea that the body has the ability to heal itself (Eller, 2015). Some practitioners utilise occupational therapy techniques as a standalone, or in combination with other neuro-feedback interventions (Evens, 2007). Autism Spectrum Disorder is a dysregulation in brain activity, and appropriate neuro- feedback training provides possible modifications of brain activity through the monitoring of frequency levels through use of EEG study (Eller, 2015; Evens, 2007).

The following question guided the study: What are health professionals' perceptions of the utility and effectiveness of neuro-feedback treatments for regulating behavioural dysregulation and acute ambient environment among children with ASD?

\section{Method}

\section{Research design}

The study utilised an exploratory qualitative research design which map the practitioner consensus on the neuro- feedback intervention efficacy for treating behaviour dysregulation and acute sensitivity to environment activities among children with ASD. The study therefore employed an exploratory qualitative research design as this proved to be the most suitable for exploring neurofeedback intervention by which it gained knowledge and understanding through the in-depth interviews that were conducted with the participants in this field of practice (Babbie \& Mouton, 2001).

\section{Participants and setting}

Permission and ethical clearance to conduct the study were obtained from the Higher Degree Committee of the University of the Western Cape and the Senate Research Committee and Ethics Committee (Reference number: 15/4/105). The participants individually consented for study.

Informants were a purposive sample of ten neuro- feedback practitioners registered with the HPCSA. Each practitioner has a minimum of three years' practical working experience treating ASD utilising neuro-feedback as an intervention. The participants resided/worked in 
the following South African provinces: Gauteng $(n=4)$, the Western Cape $(n=4)$, the Free State $(n=1)$, and one from the Eastern Cape $(n=1)$.

\section{Practitioner profiles}

Participant 1 is a female practitioner with a degree in medicine in private practice in Bloemfontein . She has 10 years' experience as a practitioner utilising neuro-feedback specifically for ASD children of all severity levels.

Participant 2 is a female practitioner with a degree in occupational therapy in private practice in Gauteng. She has four years' experience practising neuro-feedback specifically for ASD children.

Participants 3, 5, 9, and 10 were all female practitioners with degrees in psychology in private practice in Cape Town. They all had between three and five years as practitioners utilising neuro-feedback specifically for ASD children .

Participants 4, 6, and 7 are male practitioners with a degree in psychology in private practice in Gauteng. They all had on average between six to nine years' experience as practitioners of neuro-feedback for ASD children .

Participant 8 is a male practitioner with a degree in optometry in private practice in East London. He has three years' experience as a practitioner utilising neuro-feedback specifically for ASD children of all severity levels.

The interviews were conducted in the comfort of the participants' own venue by means of Skype or in- person interviews. With consent from the participants, all interviews were audio-taped and transcribed. The duration of the interviews was about 45 to 60 minutes each.

A limitation to this study is that the neuro-feedback practitioners would be advocating the intervention. Moreover, all participants were registered with the HPCSA; however, not all practitioners utilising this intervention are registered with the HPCSA.

\section{Data analysis}

Common themes were extracted through repeated reading of and reflection on the transcripts, reflective journals, and notes. Sub-themes emerged through data reduction. The themes were then linked to the literature to gain a deeper understanding of the phenomena being explored (Steinberg, 1999).

\section{Findings}

Practitioners perceived neuro-feedback treatment to have efficacy for reducing anxiety and aggression among children with ASD; while also enhancing their communication and behavioural regulation, as well as quality of family-life. 


\section{Reductions in anxiety and aggression}

All of the neuro-feedback practitioners perceived neuro- feedback treatment to be effective for reducing anxiety levels and aggression among children with ASD. Illustrative statements by practitioners are as follows:

So after three months, we just persevered, I think we had two sessions a week, after three months that child sat so quietly that I could actually do a quantitative EEG, his behaviour changed completely, he was less hyperactive, and he was less sort of fighting. There was a definite change and I see that often with children or people who suffer from uncontrolled anger. (Participant 8)

One of the more debilitating aspects of autism is the high levels of anxiety. Most autistic children are extremely anxious and they've got these huge fetishes, you know, for instance if they walk past, it's a pen for instance and they walk past the pen say in the next 10 minutes thereafter they would then want to put the pen back where it's supposed to be. (Participant 9)

\section{Enhanced communication}

The majority of practitioners (80\%) indicated improved results with neuro-feedback treatment for communication and speech among children with ASD. The following statements are illustrative:

So autistic kids that are starting to talk and being able to talk normally and not interrupting people and being able to fit in in society. That is the direct benefit that neuro-feedback has on autistic children. And this will help the child to prepare for school. (Participant 4)

One of the more debilitating aspects of autism is the high levels of anxiety. .... neurofeedback [in] five sessions [helped] reduce the child's high levels of anxiety [improving] the child's ability to communicate, interact etc. (Participant 3)

\section{Behavioural regulation and family life}

All of the practitioners reported use of neuro-feedback to be effective in treating ASD related behavioural excesses. As examples, the practitioners observed:

[The child's behaviour] changed completely, [and with] less fighting... he was much calmer in general [and with much less of] uncontrolled anger. (Participant 7)

"He has friends, he is doing exceptionally well at school [he is ] more relaxed [than before] ... it's quite a drastic change. (Participant 2)

Since neuro-feedback directly contributes to behavioural regulation, it is logical to infer that the children communicated better with the family (Eller, 2015). Better interaction with peers, siblings, and parents has been reported for children with neurodevelopmental 
disorders treated with neuro-feedback therapies (Eller, 2015). Neuro- feedback should not be used in isolation but together with complementary non-invasive treatment therapies. 


\section{References}

American Psychiatric Association . (2013) . Diagnostic and statistical manual of mental disorders (5th ed.). Arlington, VA: American Psychiatric Publishing.

Babbie, E ., \& Mouton, J . (2001). The practice of social research . Cape Town: Oxford University Press .

Bakare, M. (2011). Excess of non-verbal cases of Autistic Spectrum Disorder presenting to orthodox clinical practice in Africa: A trend possibly resulting from late diagnosis and intervention. South African Journal of Psychology. SuidAfrikaanse Tydskrif vir Sielkunde, 17(4), 118-120.

Demos, J. N. (2005). Getting started with neuro-feedback. New York: W.W. Norton.

Eller, F . (2015). The effectiveness of neuro-feedback training for children with autism spectrum disorders. Wiesbaden: Springer Fachmedien . https://doi .org/10 .1007/9783-658-08290-1

Evans, J . R . (Ed .) . (2007) . Handbook of neuro-feedback: Dynamics and clinical applications. New York: Hayworth Medical Press.https://doi.org/10.1201/b14658

Hoffman, E. (2012). Raising a child with Autism: Exploring family support structures . Stellenbosch: University of Stellenbosch .

Kvale, S . (2010). Doing interviews . London: Sage .

Kouijzer, M. E. J ., de Moor, H. M. H., Gerrits, B . J . I., Buitelaar, J . K., \& van Schie, H. T . (2009) . Long-term effects of neuro-feedback treatment in autism. Research in Autism Spectrum Disorders, 3(2), 496-501 . https://doi .org/10 .1016/j . rasd.2008.10.003

Larsen, S . (2012). The neuro-feedback solution: How to treat autism, ADHD, anxiety, brain injury stroke, PTSD, and more. Rochester, VT: Inner Traditions/Bear.

Lincoln, Y. S ., \& Guba, E. G. (1985). Naturalistic inquiry . Beverly Hills, CA: SAGE Foundations of Psychology .

Othmer, S ., Othmer, S ., \& Kaiser, D . (1999) . EEG biofeedback . In Evans, J . R . \& Abarbanel, A . (Eds .) . Introduction to quantitative EEG and neuro-feedback (pp . 243-310) . Cambridge, Massachusetts: Academic Press . Retrieved from https://doi .org/10 .1016/B978-012243790-8/50012-2

Robbins, T. (2000). A symphony in the brain. New York: Grove Press .

Sadock, B . J ., \& Sadock, V . D . (2007) . Kaplan's and Sadoc's synopsis of psychiatry: Behavioural sciences/clinical psychiatry (10th ed.). New York: Lippicott Williams and Williams.

Scolnick, B . (2005) . Effects of electroencephalogram biofeedback with Asperger's syndrome . International Journal of Rehabilitation Research. Internationale Zeitschrift fur Rehabilitationsforschung. Revue Internationale de Recherches de Readaptation, 28(2), 159-163 . https://doi . org/10 .1097/00004356-20050600000010

Sichel, A . G ., Fehmi, L . G ., \& Goldstein, D . M . (1995) . Positive outcomes with neurofeedback treatment in a case of mild autism. Journal of Neurotherapy, 1(1), 60-64 . Retrieved from http://isnr .org/uploads/(1-1) .pdf https://doi .org/10 .1300/ J184v01nO1_08 
Springer, P ., van Toorn, R., Laughton, B ., \& Kidd, M . (2013). Characteristics of children with pervasive developmental disorders attending a developmental clinic in the Western Cape Province, South Africa . South African Journal of Child Health, 7(3), 95-99. http://www .sajch.org.za/index.php/ SAJCH/article/view/530

Steinberg, S . (1999). An introduction to communication studies. Cape Town: Juta \& Co Ltd.

Tanguay, P. (2000). Pervasive developmental disorders: A 10 year review. Journal of the American Academy of Child and Adolescent Psychiatry, 39(9), 1079-1095 . https://doi. org/10 .1097/00004583-200009000-00007

Twoy, R., Connolly, P ., \& Novak, J . (2007) . Coping strategies used by parents of children with autism. Journal of the American Academy of Nurse Practitioners, 19(5), 251260. https://doi .org/10.1111/j.1745-7599.2007.00222 .x

Yucha, C., \& Gilbert, C. (2004). Evidence-based practise in Biofeedback and Neurofeedback. Wheat Ridge, CO: AAPB . 